\title{
NIRS/NUTBAL nutritional profiling system for grazingland animal management
}

\author{
J Stuth, R Lyons \\ Department of rangeland ecology and management, Texas A\&M university, \\ College Station, TX 77843-2126, USA
}

Rapid, accurate systems for monitoring the nutritional status of animals has been a major limitation to nutritional management of a vast majority of the world-wide population of livestock. Most practical methodology in the past has focused on hand-plucked samples which attempt to simulate diets selected over a landscape. This system generally leads to lower estimates of diet quality than those selected by the target animals. Recently, Lyons and Stuth (1992, J Range Manage, 45, 238244) developed methodology which accurately predicts dietary crude protein (CP) and digestible organic matter (DOM) via near infrared reflectance spectroscopy (NIRS) scans of dried, ground feces of free-ranging cattle. The system has been refined resulting in a nation-wide service which allows livestock producers to collect fresh fecal samples, ship the samples in insulated mailers via 2-day express mail and receive diet quality estimates 48-72 hours after arrival at the Grazingland Animal Nutrition Lab at Texas A\&M University. The lab has ascertained that irradiation of samples (6 megarads) does not affect prediction of diet quality potentially allowing analyses of diet quality not only in the USA but in regions of the world where nutritional profiles are poorly understood and forage testing infrastructure limited.

A computerized decision support system was also developed to assess the nutritional balance of cattle, sheep, goats and horses. The NUTBAL-Nutritional Balance Analyser was designed to link the NIRS technology with site specific conditions of an individual herd to allow determination of crude protein, net energy of maintenance/gain status of animals and least-cost analysis of potential feedstuff to alleviate nutrient deficiencies. NUTBAL uses the NRC system for assigning nutrient requirements as modified by Fox et al (1988, J Animal Sci, 66, 1475-1495). However, dry matter intake is driven by a modified indigestible dry matter fill system which is adjusted for animal kind, class, breedtype, age, sex, weight at neutral body condition score, physiological stage adjusted for latter stages of pregnancy and level of milk production using a 16-week lag factor, nutrient concentration, $\mathrm{DOM} / \mathrm{CP}$ ratio (growing animals only), terrain conditions, coat conditions, maximum air temperature, windspeed, metabolic modifiers, ionophores and available forage. Average daily gain is predicted for all classes of cattle.

NUTBAL has three major modules. To support a specific case analysis, the animal attribute module stores information on age classes of each kind of animal and critical features of various breeds such as frame score, hide thickness, maximum hair length, net basal metabolism adjustment, fill adjustment, peak milk yield and fiber yield. A feedstuff database reflecting nutritional values is available with a large number of concentrates and roughages that can be expanded by the user. The case description module allows the user to enter the necessary information previously listed along with NIRS predicted forage quality values and allocated feedstuffs. Should nutrient imbalances occur, the user can choose a suite of feedstuffs, characterize feeding waste, market value, processing fees, storage costs, and feeding costs and set upper or lower allocation constraints for each feed. A simplex algorithm processes the information on nutrient requirements, indigestible dry matter fill, DOM/CP ratio and feedstuff characteristics to determine a least-cost solution to meeting livestock performance goals.

The NIRS/NUTBAL system has been successfully applied to tropical pastures, subtropical rangeland and marshes, temperate native prairie and woodlands, foothill woodlands, mountain meadows, forestland, annual grasslands, small grain pastures, coolseason grasses and stored forages. Currently, over 300 ranchers in 21 States are using the system in the USA. 